\title{
Ocorrência de Salmonella Spp em Alimentos Não Processados e em Produtos Industrializados e Identificação Sorológica Das Cepas Isoladas.
}

Adriana Proença (I), Fernanda Nunes (I), Nayara Pereira (I), Michelle Menezes (I), Renata do Val (I), Janete Walter Moura (I)

(I) TECAM Laboratórios - TECAM Laboratórios (Rua Fábia, 59 - São Paulo - SP)

\section{Resumo}

A Salmonella spp é um dos micro-organismos mais amplamente distribuídos na natureza e um dos principais agentes envolvidos em surtos de origem alimentar. O homem e os animais, entre os quais aves, suínos e bovinos, são os principais reservatórios naturais dessa bactéria. A ocorrência de doenças transmitidas por alimentos (DTAs) é uma preocupação mundial e, apesar dos avanços tecnológicos, o controle de surtos envolvendo micro-organismos patogênicos, especialmente Salmonella spp, continua sendo um desafio. A caracterização antigênica representa uma ferramenta importante na epidemiologia de Salmonella spp, permitindo assim, o conhecimento e controle quanto à fonte de disseminação. Este estudo teve como objetivo verificar a prevalência de Salmonella spp em alimentos processados e alimentos não processados nas amostras analisadas em rotina pelo TECAM Laboratórios. O preparo das amostras para análise microbiológica e as determinações analíticas foram realizadas de acordo com as normas ISO 6579:2002 e AOAC 2004.03. Os isolados de Salmonella foram sorotipados pelo Instituto Adolfo Lutz de São Paulo, de acordo com o esquema de Kauffman-White. De um total de 5309 amostras analisadas, sendo $92 \%$ alimentos processados e $8 \%$ alimentos não processados, verificou-se a contaminação por Salmonella spp em $1 \%$ das amostras, representando $0,3 \%$ em alimentos processados e $0,7 \%$ em alimentos não processados. As cepas isoladas foram submetidas à 
análise de caracterização antigênica, chegando-se aos sorotipos Salmonella entérica subespécie enterica (O:4,5), S. Typhimurium, S Agona, S Montevideo, S Tennessee e S Senftenberg.

Palavras-Chave: Salmonella spp, alimentos, identificação sorológica Agência de Fomento: 